\title{
Research operating test of railway vehicles
}

\author{
Bogdan Żółtowski ${ }^{1, *}$ and Leonel F. Castaneda ${ }^{2}$ \\ ${ }^{1}$ University of Technology and Business, Jutrzenki 135 Street, 02-231 W arsaw, Poland \\ ${ }^{2}$ EAFIT University, Facoulty of M echanical Engineering, Carrera $49 \mathrm{~N} 7$ sur 50, Colombia
}

\begin{abstract}
This article shows the results obtained during the implementation of a portable diagnosis system to the maintenance routines of the passenger vehicles and permanent track of the $M$ etro train, which made it possible to evaluate such aspects as: safety, comfort and technical condition of the track-vehicle interphase. The reports given in this evaluation allowed the identification and the arrangement of the track sections according to its technical condition, relating thus the track and vehicle condition parameters to the estimators connected with the passenger vehicles dynamics.
\end{abstract}

\section{Introduction}

The manufacturers of means of railway transport invest vast amounts of money in the construction of fast, safe, comfortable and efficient passenger vehicles. The methods and means of modern technical diagnostics allow to maintain the ability state of the means of railway transport through constant monitoring of their technical state. They also allow to examine the performance of requirements determined for the means of railway transport in the range of effective safety and comfort standards.

A ccepting the vibration signal as the basis of the description and examination of the dynamic state changes of the railway transport system at work, the state of running safety and comfort, state changes of chosen assemblies of the railway system, and state changes of the foundation and railway tracks were evaluated.

During the realization of separate tasks in this work, we used the available, and created new, procedures of diagnostic signals acquisition and processing for state evaluation, created and practically verified the method of measuring points selection for vibration diagnostics, proposed modernized procedures in the range of diagnostic sensitivity examination and boundary values determination for measured signals, verified chosen diagnostic models, and analyzed chosen prognosis methods for the needs of next diagnosis date determination.

In the range of statistic handling of measuring data, we used available but modernized procedures of MATLAB, EXCELL, STATGRAPHIC software, examining the correlations, regressions, decompositions, models - everything at the stage of diagnostic concluding. For the detection and location of damages we used new procedures of the Principal Component A nalysis (PCA) methodology and the Singular V alue Decomposition (SV D) method.

The length of the power engine is about $22.8 \mathrm{~m}$. All the vehicles have the width of $3.2 \mathrm{~m}$ and height of $3.8 \mathrm{~m}$ (the height to the roof without the pantograph). Each car of the vehicle is based on two trucks of two axis through four pneumatic cushions which maintain settled height of the vehicle regardless of the load. T wo trucks of the power engines have a power transmission system on each axis, consisting of a transmission and an electric engine, the latter being hung on a special construction. The supply of compressed air to the unit consisting of three individual cars is

\footnotetext{
* Corresponding author: bogdan.zoltowski@uth.edu.pl
} 
realized by a piston compressor. Each car is connected with a short connector which can be removed in a workshop. One connector with a bumper is placed at the end of a car, which allows to connect cars into sets.
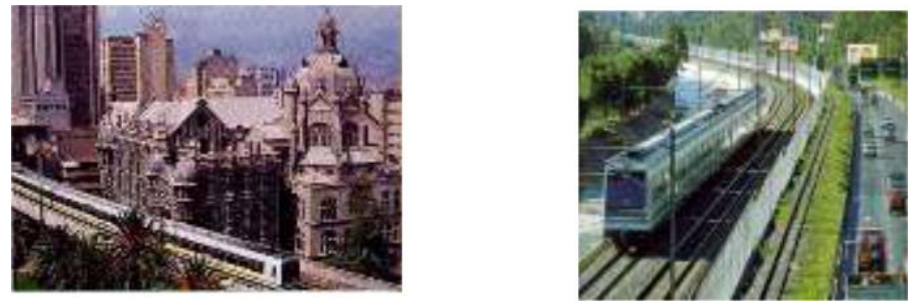

Fig. 1. Cars of metro train on the route.

The damages of wheels of a railway system most often undergo ability tests in the effective planning-preventing exploitation system. The supervision of the wheelrail system technical state has the following parameters:

- nonalignment,

- radial aberration,

- circularity,

- impurities,

- waviness,

- flatness,

- surface loss (spalling),

- material loss.

M ost often encountered damages connected stemming from the wheel-rail co-operation are: flatness (due to braking and lack of greasing of the vehicle), periodic nonalignment and circularity. The tasks and responsibilities of an apt and safe railway system of M ETRO system are guaranteed by the used modern railway traffic supervision system of M ETRO.

\section{Railway dynamics car study}

The description and determination of basic parameters for a multi-criteria safety, comfort and state changes system for railway cars, requires mainly the estimation of reactions in motion between the wheel and the rail, as well as the dynamics of car motion, which is included in the analysis and synthesis of the railway car dynamic state. Bilateral reactions between the moving object and the base affects not only the vibrations of the rolling stock, but also the power transmission system and the body.

$\checkmark$ ibroacoustic effects - vibrations and noise - present during the vehicle's motion on railway tracks are the source of information on dynamic state, and running comfort and safety. Source identification of those effects is not al ways easy. There are geometric irregularities appearing on the vehicle's and track's rolling elements during their use, which can cause transverse displacement and inclination of the vehicle, longitudinal displacement, swaying, snaking, etc., which are spread onto frames of the truck, and then onto the car (Fig. 2). 


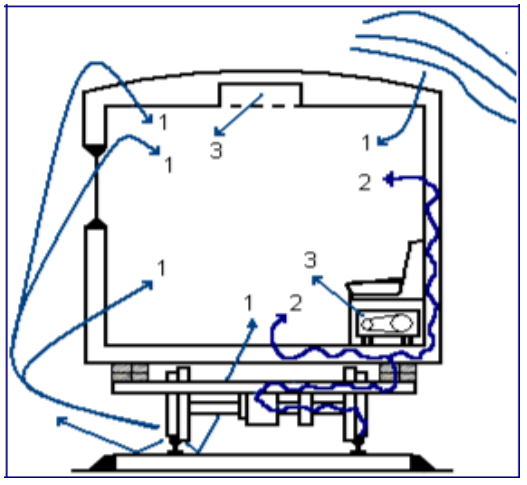

Fig.2. Lines of noise and vibrations transmission to the passengers.

For the dynamic analysis of railway cars in specific exploitation conditions, different complex computer programs have been used recently, such as: Vampire, A dams/Rail, Gensys, Simpack, M iniprof Wheel A nd Rail (Fig. 3).

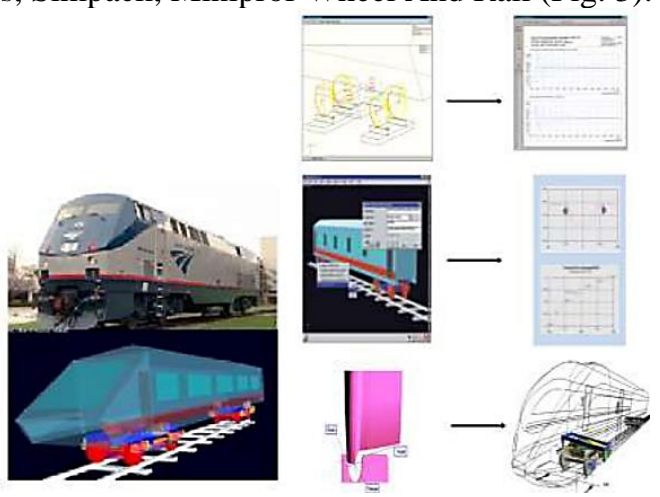

Fig. 3. Example of dynamic modeling for railway engineering.

Fig.4 shows complex computer models created and used for the running dynamics analysis of a railway car.

a)

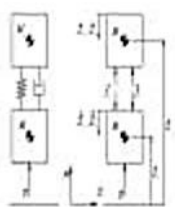

c)

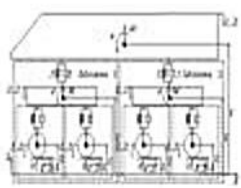

t)

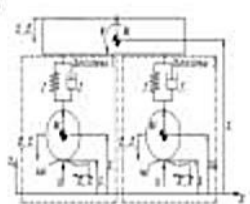

d)

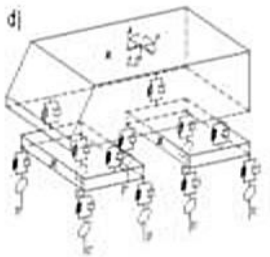

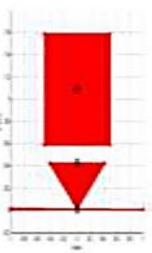
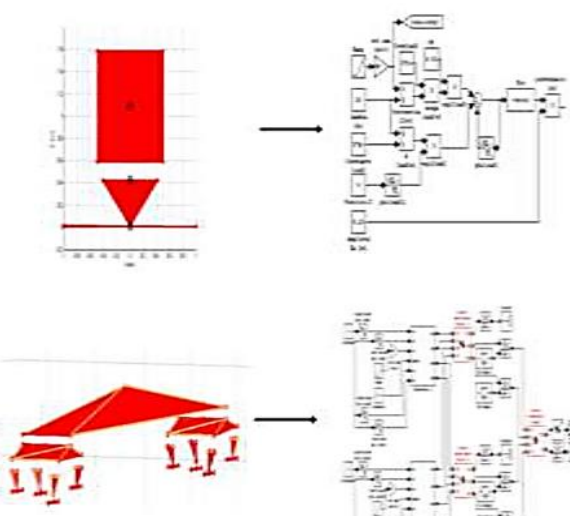

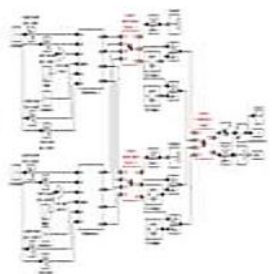

Fig. 4. Computer models for train dynamics testing. 
These models are described with the use of physical parameters, such as: damping, mass and rigidity, they should, therefore, contain real values of these parameters. The determination of these parameter values takes place at a special laboratory station.
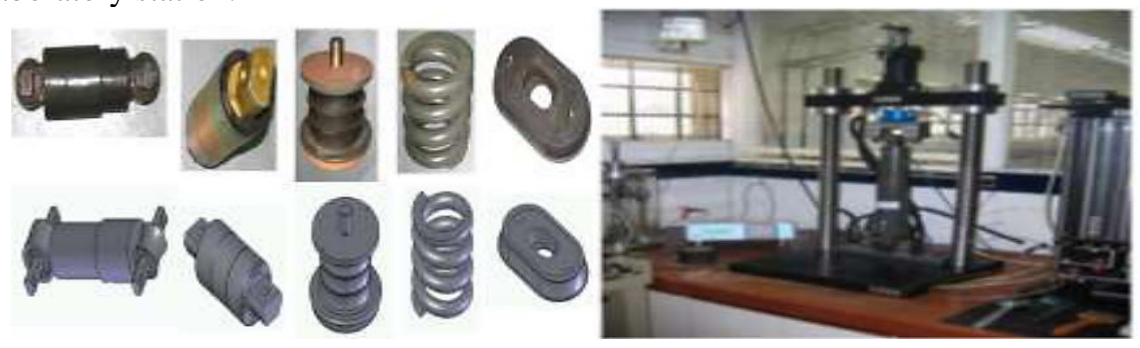

Fig. 5. Physical parameters estimation for train elements.

Computer models should reflect physical objects as well as possible, thus each simulation needs to be verified experimentally. The experimental manner of free vibration frequencies determination for a railway car of METRO (empty and loaded), for the purpose of this work was carried out with the help of a research team (GEMI).

\section{Running safety and comfort}

In order to achieve the reliability and readiness of a system, and to lessen the risk of derailment of a train during its exploitation, there is a need to implement the modern technical diagnosis method which allows to maintain the life cycle through constant monitoring of the technical state, which determines the fulfillment of running safety and comfort requirements for transportation systems.

Each new railway system is evaluated in the aspect of running safety and comfort through measuring acceleration and forces on different masses of the railway car. The existing norms for the evaluation of these systems present procedures for the acquisition, register, analysis and comparison between the dynamic measure and boundary value.

a)

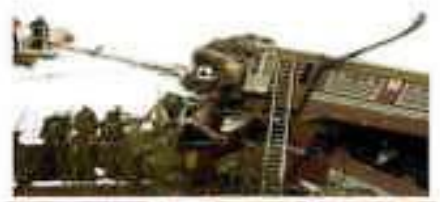

c)

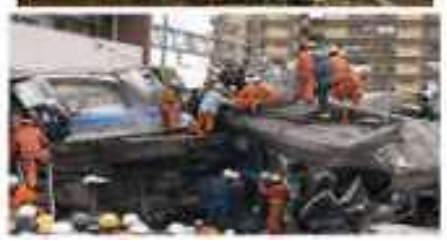

b)

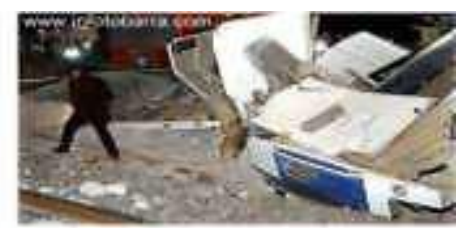

d)

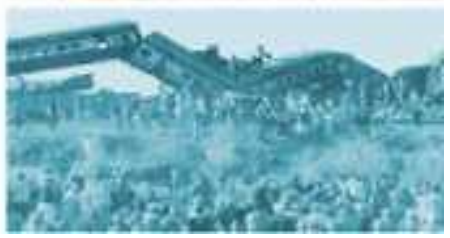

Fig. 6. Train crashes: a) Precot, B elgium - 2001, b) Tobarra, Spain - 2003, c) A magasaki, J apan - 2005, d) Fatehgarh, Punyab, India - 2000.

In order to evaluate the vehicle's safety, it is necessary to install sensors allowing to determine measures connected with the train's motion dynamics. The UIC -518 norm describes procedures for safety evaluation, and indicates two measurement methods which allow the determination of relations between the values of vertical forces $Q$ and shearing forces $Y$ present during wheel-rail co-operation. 
A ccording to the general rule, safety in the train is evaluated on the basis of derailment criterion through wheel displacement values on the upper surface of the rail. The distribution of vertical and shearing forces illustrating the presented relations is show in the Fig. 7.
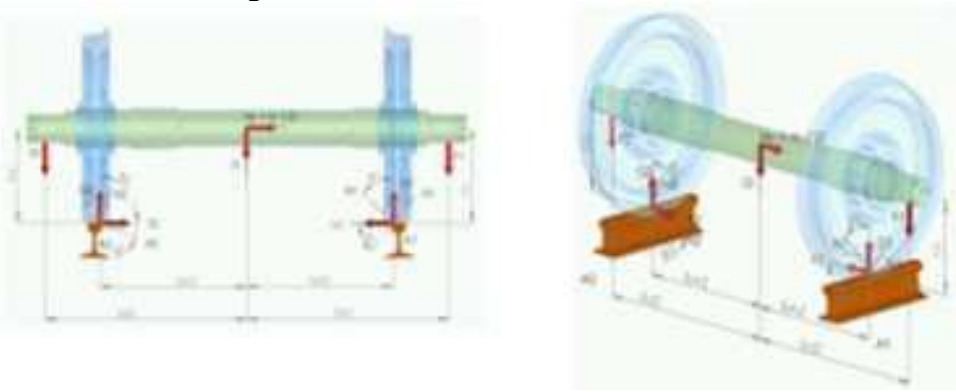

Fig. 7. Force distribution of the wheel-axis set on the rail.

There are different methods in the world used for measuring vertical and shearing forces present during wheel-rail co-operation. One of those methods is a Swiss SBB method which consists in installing extensometer sensors on the rail's surface between two sleepers, and for result register, a proper configuration of Wheatstone bridge is used (Fig.8).

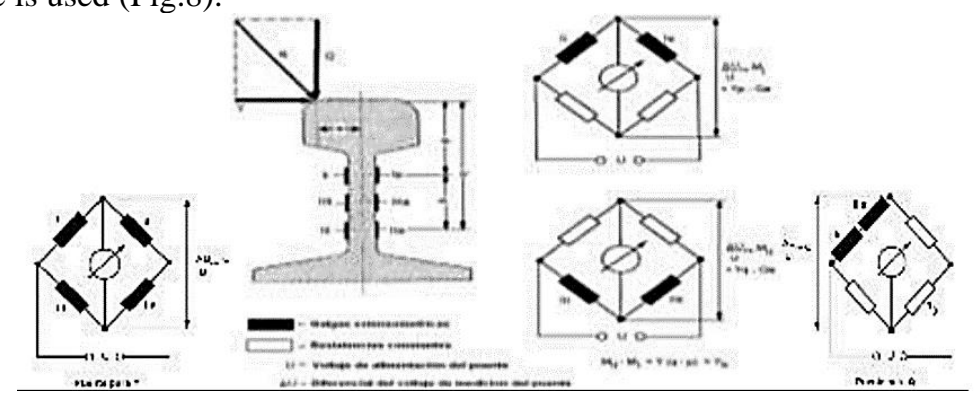

Fig. 8. SB B M ethod for force measurement.

The presented method was used during the research for measuring reaction forces between the wheel and rail, which according to the subgrade quality exploitation data allowed to draw cause-and-effect conclusions for the needs of the constructed railway cars state evaluation system.

There are many practically used terms concerning comfort in the railway transport, such as: passenger comfort, running comfort, running quality, and running indicator. Running quality is affected by physical and human factors, as well as the car's dynamic motion. Whilst running comfort and running quality indicators contain only dynamic parameters of the car's motion. Most often they are acceleration and railway car's motion linearity changes, and these parameters are normalized in available international norms.

Passenger vehicles comfort is evaluated on the basis of the UIC - 518 norm, considering the conditions:

- the implementation on trial lines (linearity of the track, geometric parameters quality of the track, velocity, lack of inclination),

- the geometry of wheel-rail contact,

- measures connected with the vehicle's dynamics,

- conditions for automatic and statistic data processing,

- dynamic measures evaluations, 
- boundary values of comfort indicators.

Besides the norms of railway vehicles comfort evaluation, in which comfort is most often described with the use of acceleration, there supplementary norms which describe the noise level caused by the train inside and outsider the vehicle. It is recommended that noise level researches are carried out according to the following options:

- noise level measurement inside the vehicle on running,

- noise level measurement inside the empty vehicle during the standstill,

- noise level measurement outside the vehicle on running,

- noise level measurement outside the vehicle during the standstill.

The fig. 9 shows an example of noise level measurement inside and outsider the car. For the practical uses of METRO train cars comfort evaluation, the following procedures were used: the evaluation of the influence of vibrations on the running comfort with the use of UIC - 518 norm, the evaluation of the influence of noise level on passenger comfort with the use of APTA norm.

To evaluate the comfort, seven estimators for passenger cars need to be determined based on the measurement of vertical and transverse acceleration. They are: $y: * q(99,85 \%), y: * q(0,15 \%)$, sy:*q, y:*qst, $z: * q(99,85 \%), z: * q(0,15 \%)$ y sz: $*$. Ride comfort evaluation estimators are determined both for straight and curved sections on the route of a passenger vehicle.

The presented considerations from the range of railway systems safety and comfort, as well as norms connected with their evaluation, gave the basis for creating procedures to conduct measurements of velocity in railway cars, and the noise level inside and outside the passenger vehicle.

The manner of data acquisition and processing for safety and comfort indicators calculation, as well as valid boundary values, were further used in METRO railway cars researches.

\section{Methodology of train cars diagnosis}

The realization of the main task of the technical diagnosis of train cars system requires the determination of relations between the state features and signal parameters. Therefore, the choice of state features (necessary and available) and signals with their estimators for the examined cars has to be made. From the relations present between them, all the necessary criteria values for the safety, comfort and technical state changes
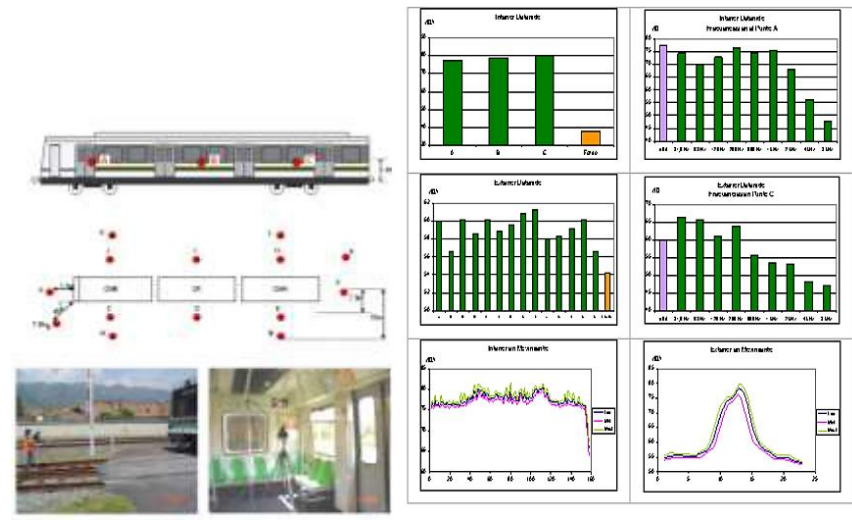

Fig. 9. Noise level measurement inside and outside the railway vehicle. 
System will be determined for the examined railway system. The methodology of the conducted research is based mainly on the UIC-518 international norm which describes rail vehicles working conditions for safety and comfort research, such as: vehicle's velocity, state of the rail, object's dynamic and static state, etc. the research was realized in real exploitation conditions of the transport system, and were carried out on 16 trains.

In the research, the newest methods of train state features measurement and description were used, as well as available modern means and methods for object's dynamic state parameters evaluation. Also, the ways of the acquisition, processing and diagnostic conclusion of changeable train ride quality parameters are the newest achievements in the field of machines' technical diagnostics.

In the range of this work's considerations, many original procedures facilitating the realization and description researches where created, including:

- method of choosing measurement points for measured signals,

- methods of determining boundary values for signal estimators,

- methodology of information reduction for passive experiment testing amended methodology of Principal Component A nalysis PCA for the size reduction of symptom observation matrix,

- multidimensional graphic method of vector and own values presentation,

- decomposition method according to the special SVD (Singular Value Decomposition) values for damage detection and location,

- technical state evaluation probabilistic model,

- method of symptom reliability determination for the examined technical system,

- method of determining the indicators of train exploitation quality,

- $\quad$ method of forecasting for determining the next date of diagnosis.

Diagnostic concluding leading to a pertinent diagnostic decision requires the association of good state features describing the object's structure with the damageoriented symptoms of the state represented by valid diagnostic signal estimators. Therefore, the acquired data needs to undergo various processes during their archivization, information selection, extraction of information on the state in boundary values determination, modeling, reliability and risk determination, or the optimization of further diagnosis dates.

A large quantity of diagnostic information from the railway subgrade testing, noise and vibration testing of the railway system, underwent a statistic process (BEDIND, PCA, SVD, cause-and-effect relations modeling) within useful information extraction as well as for the need of determination of basic indicators characteristic for the exploitation quality.

\section{Research results}

To examine the running safety and comfort, a monitoring system was installed, which allowed to acquire and register the data: vibration acceleration, forces and velocity of the vehicle. The sensors of acceleration were installed on the train's sprung mass, i.e. the wheel-axis set, truck frame and the car of the vehicle. The force sensors were placed at the level of the guiding truck, and the velocity signal was provided from the control system of the railway unit. The configuration of sensors, sampling method, filtering and statistic calculation of estimators, were carried out according to the rules of UIC international norm.

The measurement on each passenger vehicle was carried out in real exploitation conditions, where the monitoring system registered continuously data from different rides of trains (Fig. 10). 


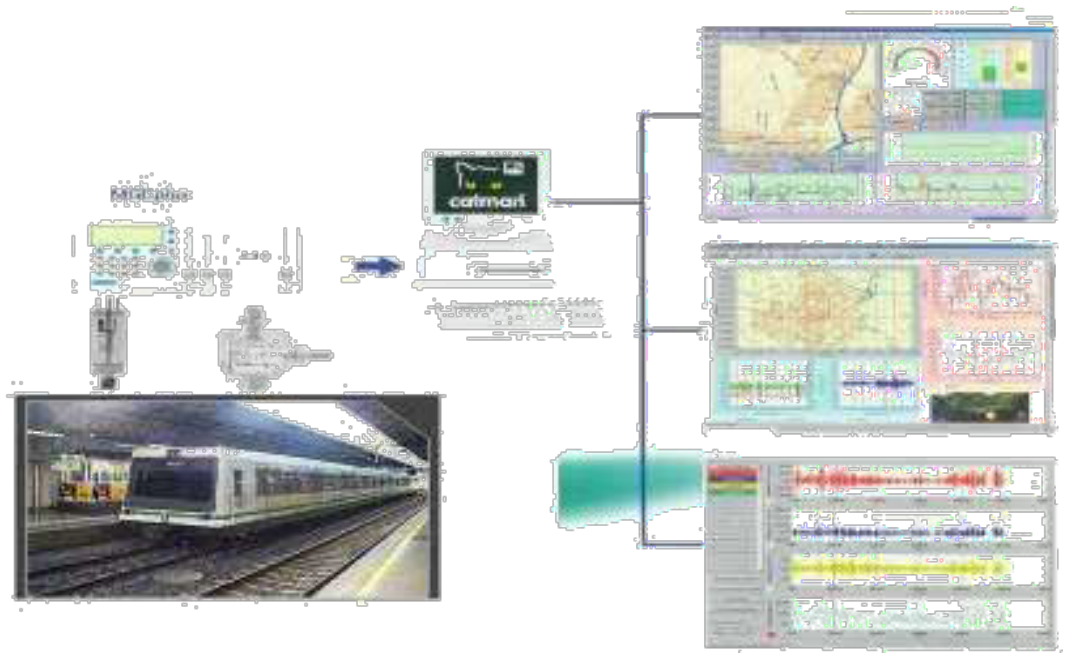

Fig. 10. M easurement System for evaluating safety and comfort of M ETRO vehicles.

For the research, the following data acquisition elements were used:

- 4 force sensors HBM U2B/100,

- 8 one-way acceleration HBM B 12/500,

- M GC Plus equipment of HBM company,

- 8 interface cards between M GC Plus and CA TM A N program type A P810,

- 4 cards for processing data from force sensors, type M L 801,

- current generator of 110-220V AC IK V A,

- voltage regulation system UPS $120 \mathrm{~V}$ ac/60Hz,

- computer with CATMAN (5.0 R3) software of HBM company.

The above elements allow to acquire very complex information necessary to implement the UIC-518 norm In the examined railway system. As the result of UIC518 norm implementation, statistical reports on the car's safety and comfort evaluation as well as the track usage have been created. Example results of the research are shown in the Fig. 11 abc.

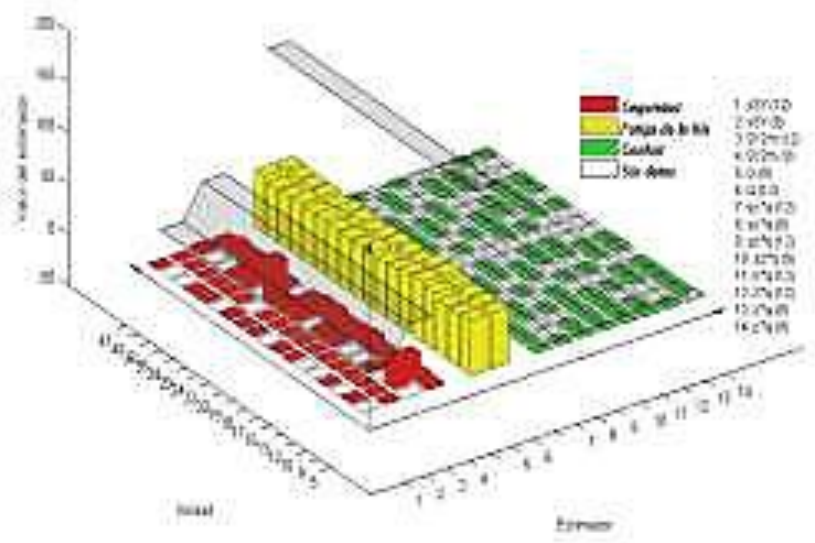

Fig. 11a. The implementation of the UIC-518 norm on straight sections. 


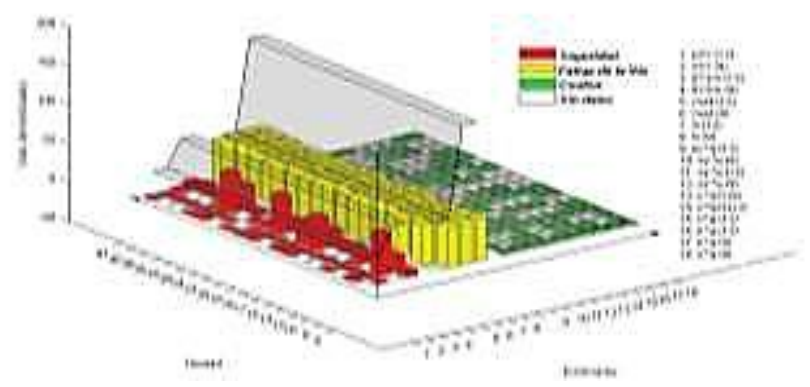

Fig. 11b. The implementation of the UIC-518 norm on curved sections of a large radius.

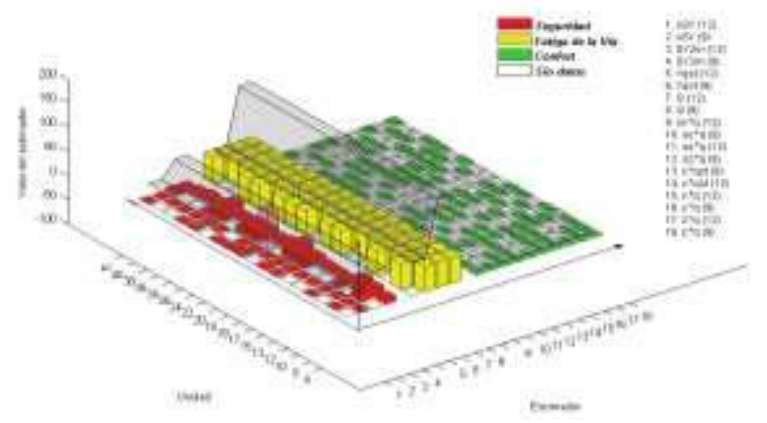

Fig. 11c. The implementation of the UIC-518 norm on examined sections.

The results of the research of the railway subgrade technical state characteristics, as well as many vibration parameters and noise are the result of using many specific procedures and algorithms of technical diagnostics. The software for data processing built based on available procedures in different programs in the field of acquisition, processing, evaluation of storage, was created for the need of storing all data from 17 examined objects.

The results of statistical researches of a rich informative material from METRO trains researches provided basic relations and values being the basis of the constructed multi-criteria system for the evaluation of running safety and comfort of METRO trains.

\section{Portable diagnostic system - PSD}

The realization of all the tasks allowed the preparation and construction of a portable diagnostic system. PSD allows to evaluate the safety and comfort state, as well as, with the help of estimators related to safety and comfort evaluation, enables damage detection in the wheel-rail system all along the railway route. It allows to optimize all the maintenance actions for cars, maintenance of the track, wheel-rail system cooperation evaluation, giving premises to use the strategy in accordance to the technical state.

PSD connected with the central traffic control system is a system managing all the information connected with the maintenance of the cars' technical state, wheelrail system technical state, track technical state, and the whole railway system in general. Saved in the PSD, the history of the state of all the straight and curved sections as well as the wheels of the passenger vehicle, allows to analyze the data, 
compare them to the measured estimators boundary values, forecast state changes and related operation, maintenance and investment works.

The construction of PSD stems from the range of tasks to be realized and diagnosis procedures based on the UIC -518 international norm which possesses all the procedures for passenger vehicles testing from the point of view of its dynamic behavior for track wear evaluation, safety and comfort of the ride in exploitation natural conditions. M odules of which PSD is made are as follows:

- sensors module,

- signal processing module,

- safety and comfort evaluation module,

- wheel-rail technical state evaluation module,

- damage detection module,

- auxiliary decision-making module,

- forecast module,

- presentation module.

For example, the damage detection module in PSD contains the tools:

- monitoring the values of safety and comfort estimators,

- monitoring the values of frequencies which describe wheel-rail co-operation,

- detection of maximal forces on the tested track,

- monitoring the values of forces generated by railway switches on the passenger vehicle.

The decision-making module is based on the analysis of correlation between the UIC-518 norm estimators, which evaluate the comfort and safety of the vehicle, and the track's geometric parameters for the tested railway system. The module additionally receives information provided from the safety and comfort evaluation module and wheel-rail technical state evaluation module. This module distinguishes track sections which do not meet the requirements of running safety and comfort in the face of requirements by the UIC -518 .

The presentation module is an interface between the user and the PSD system. All the information from separate modules is placed there. It is connected to the traffic control system in the company. The module is a safety system which has access to the data base, data loading forms, user help, reports and report generation in Spanish and English. Fig. 12 shows the initial PSD screen where the upper window allows access to all the module and functions. The program $\mathrm{Has}$ a safety system which, through the necessity of giving one's name and password, does not allow unauthorized personnel to access the program. PSD is the basic tool for strategy implementation according to the technical state in the railway vehicles.

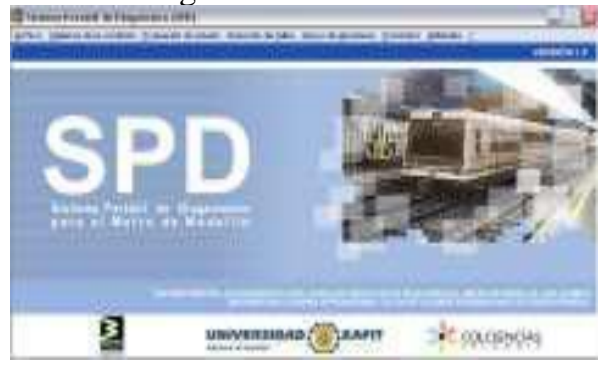

Fig. 12. PSD main screen. 
The suggested railway vehicles of technical state research has been adjusted to the exploitation natural conditions and it uses estimators both advised by the UIC 518 norm and new vibration state estimators. A lso, the final product of the work, in the form of the portable diagnostic system, implemented in the railway vehicles exploitation system, allows the implementation of the exploitation diagnostic system in enterprise.

\section{Summary}

In researches of his work, we considered the problem of creating and practical verifying an evaluation system of running safety and comfort of railway vehicles. The created evaluation system strays in its range from the requirements of the UIC 518 norm in the field of requirements concerning the conditions of research performance and range. In this work, we have performed the evaluation of motion safety and running comfort due to the requirements of the UIC -518 norm for rail way vehicles in real usage conditions, and not on special rails or fields proposed by the manufacturers of these transportation systems.

The proposed system of state examination of railway vehicles was adjusted to real exploitation conditions, and it uses both recommended by the UIC-518 norm and new estimators of vibration state. Also, the final product of this work, in the form of a portable diagnostic system implemented into the exploitation system of railway vehicles, allows the introduction of the exploitation diagnostic system into the railway vehicles enterprise.

The realization of detailed tasks of the presented conduct procedures allowed to create a multi-criteria system for the evaluation of railway vehicles state evaluation.

\section{References}

[1] L. F. Castaneda, Monitoreo Multidimensional de la Interfase Vía-Vehículo de un Sistema Ferroviario, Congreso Internacional de M antenimiento - A CIEM, Bogotá, Colombia, (2007)

[2] L. F. Castaneda, Multicriterial system for evaluating the safety and comfort in railway vehicles, Ph.D thesis, UTP, Bydgoszcz, (2007)

[3] B. Żółtowski, The Fundamentals of Machine Diagnostics, ATR, Bydgoszcz, (1997)

[4] B. Żółtowski, L. F. Castaneda, Portable diagnostic system for the metro train, Diagnostyka, nr 1(37), Olsztyn, p. 39-44, (2006)

[5] B. Żółtowski, Energetic Measures in Machine Diagnostics, Baltechmasz, Kaliningrad, p. 290-302, (2006)

[6] B. Żółtowski, Diagnostic system for the metro train, ICME, Science Press, Chengdu, China, p. 337-344, (2006)

[7] B. Żółtowski, L. F. Castaneda, Sistema Portail de Diagnostico para el Sistema Metro de Medellin, VIII Congresso International de M antenimiento, Bogota, Columbia, (2006)

[8] B. Źółtowski, Diagnostic system maintenance the ability of machines, Eksploatacja i Niezawodność, Nr 4 (36), p.72-77, (2007)

[9] B. Zoltowski, L. Castañeda, G. Betancourt, Monitoreo Multidimensional de la Interfase Via-Vehículo, Congreso Internacional de Mantenimiento, ACIEM, Bogotá, Colombia, (2007) 